Revue d'histoire de l'Amérique française

Q REVUE D.HISTOIRE DE L'AMÉRIQUE FRANÇAISE

DUMONT, Micheline, Michèle JEAN, Marie LAVIGNE et Jennifer STODDART, (le Collectif Clio) L'histoire des femmes au Québec depuis quatre siècles. Montréal, Éditions Quinze, 1982. 521 p. $18,95 \$$

\title{
Jean-Jacques Simard
}

Volume 38, numéro 1, été 1984

URI : https://id.erudit.org/iderudit/304244ar

DOI : https://doi.org/10.7202/304244ar

Aller au sommaire du numéro

Éditeur(s)

Institut d'histoire de l'Amérique française

ISSN

0035-2357 (imprimé)

1492-1383 (numérique)

Découvrir la revue

Citer ce compte rendu

Simard, J.-J. (1984). Compte rendu de [DUMONT, Micheline, Michèle JEAN, Marie LAVIGNE et Jennifer STODDART, (le Collectif Clio) L'histoire des femmes au Québec depuis quatre siècles. Montréal, Éditions Quinze, 1982. 521 p. 18,95 \$]. Revue d'histoire de l'Amérique française, 38(1), 101-101.

https://doi.org/10.7202/304244ar services d'Érudit (y compris la reproduction) est assujettie à sa politique d'utilisation que vous pouvez consulter en ligne.

https://apropos.erudit.org/fr/usagers/politique-dutilisation/ 
DUMONT, Micheline, Michèle JEAN, Marie LAVIGNE et Jennifer STODDART, (le Collectif Clio) L' histoire des femmes au Québec depuis quatre siècles. Montréal, Éditions Quinze, 1982. 521 p. 18,95\$

Je connais mal l'historiographie québécoise. Aussi excusera-t-on mon étonnement après la lecture de ce gros ouvrage. Depuis mes fréquentations de Groulx et de certains ouvrages marxistes du milieu de la décennie passée, je n'avais rien lu de comparable, et je m'imaginais que plus personne n'osait se servir de l'histoire à des fins si étroitement et si manifestement apologétiques, exemplaires, didactiques. Je croyais que l'aptitude à dissimuler ses engagements envers «notre maître, le présent tel qu'il devrait être» faisait désormais partie des compétences historiographiques banalisées. Je me trompais.

Quiconque sera capable d'endurer le petit doigt censeur et inquisiteur que secouent sans répit les auteurs sur l'histoire des femmes, de siècle en siècle, possédera une tolérance à l'anachronisme et à l'ethnocentrisme beaucoup plus grande que la mienne. Le procès des «hommes» étant affaire classée, ce sont donc ici des femmes qu'on traîne devant le banc: Madeleine de Verchères? Coupable. Les prostituées? Non coupables. Celles qui tuent leurs enfants et leurs maris? Des maquisardes - non coupables. Religieuses, membres des Cercles des fermières? Sentence suspendue, circonstances atténuantes. Et ainsi de suite. Quand on vous dit que la société de la Nouvelle-France ignorait les vertus de la co-gestion familiale, vous réalisez avoir affaire à des gens(es) capables de féliciter les Esquimaux de ne pas avoir inventé l'ordinateur ou de leur reprocher leur ignorance de la démocratie athénienne. L'attitude la plus généreuse, devant ce genre d'écriture, consiste à interrompre la lecture et à se retirer sur la pointe des pieds avant que les déformations intellactuelles ne se transforment en un terrorisme intellectuel dont vous risquez d'être la prochaine victime.

C'est donc ce que je ferai - à moitié, puisque le devoir m'imposait de lire le livre d'une couverture à l'autre. Un dernier murmure, en partant: j'y ai glané, dans les interstices entre la ligne juste et le bien-penser, beaucoup d'informations intéressantes sur la condition des femmes au Québec, rassemblées à partir de sources éparpillées mais bien connues pour la plupart. On y trouve aussi des données plus neuves et plus rares sur tout le domaine de la reproduction sociale: rituels d'accouplement et d'élevage des animaux susceptibles d'humanité, socialisation, éducation, santé, bien-être, entraide, etc. Ces aspects sont souvent négligés dans les travaux de synthèse historiographique depuis quelques années, focalisés de manière peut-être un peu obsessive sur la «production». Malgré tout, il est donc possible d'observer ici l'extraordinaire fécondité du courant «d'histoire des anonymes» qui a tant fait pour le renouvellement de la recherche et de l'écriture contemporaines sur le passé. Cette fécondité résiste aux espèces connues d'épistémologie contraceptive. 